\title{
Nominalism Meets Indivisibilism
}

\author{
JACK ZUPKO
}

Nominalists, it is said, are defined by their opposition to the needless multiplication of entities. For most fourteenth-century nominalists, parsimony was in the first instance a logico-semantic matter, raising the question of how one should explain the truth conditions of sentences without assuming any kind of strictly isomorphic relation between individual sentences and what makes them true. ${ }^{1}$ In their analyses of the structure of continuous spatial magnitudes, this question was presented in an especially clear and unambiguous

1. Thus Calvin Normore argues that it is misleading to see medieval nominalism solely as a campaign against real universals. It would be more accurate to say that medieval nominalists sought to economize on entities, of which real universals were but one type. See his "The Tradition of Mediaeval Nominalism," in Studies in Medieval Philosophy, ed. John F. Wippel (Washington, D.C.: Catholic University of America Press, 1987), pp. 201-217. For a detailed discussion of the nominalist ontological program as found in the writings of William of Ockham, see Marilyn McCord Adams, William Ockham (Notre Dame, Ind.: University of Notre Dame Press, 1987), pp. 3313. For a useful historical study of late medieval nominalism (whose author, it should be pointed out, "purposely disregards" what he calls "the traditional cliché of 'nominalism'," p. 152), see Damasus Trapp, "Augustinian Theology of the 14th Century: Notes on Editions, Marginalia, Opinions, and Book-Lore," Augustiniana 6 (1956): 146-274, esp. pp. 182-190. Though I am in general agreement with Normore's view, I won't take up here the controversial question of how medieval nominalism should be defined. Nor will any of the particular arguments given below depend on it. 
form: "Is it necessary to posit indivisible entities to explain the truth conditions of sentences containing terms such as 'point', 'line', and 'surface'?" Affirmative answers offered one route to indivisibilism, the thesis that continua are divisible into finitely or infinitely many indivisible parts, or mathematical atoms. ${ }^{2}$ But negative answers, besides leading to the opposing view that continua are infinitely divisible, also invited some account of how terms such as 'point', 'line', and 'surface' are to be understood, if not as standing for real mathematical points, lines, and surfaces (surfaces being indivisible in one dimension, lines in two dimensions, and points in three). The way in which such parismonious ontologies were achieved in practice, however, shows us that nominalist methodology was anything but static in the later Middle Ages, as more and more sophisticated techniques were introduced and perfected to explain the relation between terms and what they signify. This essay is addressed to one small, though representative, part of that story.

I shall focus on an example, an argument, and the reply to that argument given by a series of fourteenth-century nominalist thinkers roughly contemporary with each other: William of Ockham (ca. 12851347), Adam Wodeham (ca. 1298-1358), and John Buridan (ca. 1295-1358). ${ }^{3}$ The example concerns an ideal sphere gradually descending onto a perfectly plane surface until they come into contact, or sometimes a sphere in contact with a plane surface and rolling across it. Its function was to raise a question: Would the sphere (first) touch the plane surface at a point? This example was a commonplace in medieval literature on continua, where it most typically arose as

2. These are mathematical atoms, not physical atoms. As John Murdoch has observed, "late medieval atomism was not intended, as was that of Democritus or Epicurus, as any kind of general system which might cover or explain the natural world. . . . It was intended rather as a single facet of natural philosophy, designed simply to explain the structure of magnitudes, and specifically of space, time, and motion as magnitudes." See his "The Development and Criticism of Atomism in the Later Middle Ages," in A Source Book in Medieval Science, ed. Edward Grant (Cambridge, Mass.: Harvard University Press, 1974), p. 313. Nicholas of Autrecourt is an exception insofar as he defended physical atomism, though his views are not fully understood.

3. For the date of Ockham's death as 1347 and not (as traditionally cited) 1349, see Gedeon Gàl, "William of Ockham Died Impenitent in April, 1347," Franciscan Studies 42 (1982): 90-95. 
an argument for indivisibilism. ${ }^{4}$ Though he did not originate it, ${ }^{5}$ the sphere and plane example emerged as a standard topic in the medieval debate after it was discussed by the indivisibilist Henry of Harclay (1270-1317), who presents it in the following argument:

a sphere moved on a plane touches the plane at a point. Proof: because [between] a straight [line] and a circle, or a spherical body and a circular [body], there is nothing in common but a point, and contact [tactus] is always at something common. But the sphere is continuously moved on the plane. Therefore, it touches continuously, point after point, and through its motion describes a line. Therefore, point after point will be continuously in that line, and consequently, such a line is composed of points. ${ }^{6}$

We find a variation on Harclay's touch-at-a-point argument given somewhat later by the Franciscan indivisibilist, Walter Chatton $(1285-1344)$ :

God can make one thing truly plane in parts and another truly spherical in parts. Indeed, according to the Philosopher [De caelo 2.27.287a11-22],

4. Adam Wodeham, who is usually careful about naming his sources, refers to it only as "the common argument [communis ratio] concerning the touch of a plane by a spherical body." Adam de Wodeham Tractatus de indivisibilis 2.3.3, ed. Rega Wood (Boston: Kluwer, 1988), p. 138, lines 26-27.

5. Rega Wood has indicated to me in correspondence that the probable first appearance of this common argument in the West is in Book 6 of an anonymous Physics-commentary preserved in Erfurt, Amplonian Q.312, at fols. 9va and 10 rb. She believes that the commentary can be attributed to Richard Rufus of Cornwall. Richard, who knew Averröes's writings well, most likely found the argument in Averröes's commentary on De caelo. As Vassili Zoubov notes, in "Jean Buridan et les concepts du point au quatorzième siècle," Medieval and Renaissance Studies 5 (1961): 61-62, the example is cited not only by Averröes (De caelo 1.32 [Venice, 1560] f. 27 ${ }^{\mathrm{r}}$ with reference to 1.4 [271a]), but also by Sextus Empiricus (Adversus mathematicos 3.27-28) and Plutarch (De communibus notitiis 40.7).

6. Henry of Harclay, as paraphrased in William of Alnwick's Determinationes 2, fol. $7^{\mathrm{v}}$ (Latin text quoted in Wodeham De indiv. [Wood p. 290, n. 6]). For Alnwick as a reliable expositor of Harclay's views, see John Murdoch and Edward Synan, "Two Questions on the Continuum: Walter Chatton (?), O.F.M. and Adam Wodeham, O.F.M.," Franciscan Studies 25 (1966): 212, n. 2. Harclay's argument is also paraphrased by Adam Wodeham in his Tractatus de indivisibilibus 1.2 (Wood p. 94), as well as in his Quaestio de continuo, ed. Murdoch and Synan in "Two Questions on the Continuum," pp. 276-277, sect. 25. The latter may be an early draft of the former. Except for passages from Wodeham's De indiv. (which I quote from Rega Wood's edition and translation), all translations in this paper are my own. 
the heavens are spherical, or there would be a vacuum in the recess of the indented or protruding parts. Since it happens that those two are together, the sphere touches the plane. I ask whether [they touch] at a number of parts, or only at one. [1] If at many, then it is not a sphere, because it will be molded to the plane in its parts; this I demonstrate [as follows]: those parts make a plane, or [else] some [of them] will penetrate the plane and there will be some parts protruding into the plane and others indented. [2] If only at one, I have what [the argument] proposed [to show]; for it follows formally: only one part, therefore not many, therefore indivisible by necessity. ${ }^{?}$

The gist of the argument seems clear: a sphere and plane must touch each other at something, but not at a divisible part, since any such part is divisible into further parts, and contact between more than one part of the sphere and plane would involve the compression and/or penetration of the one by the other; therefore, the sphere and plane must touch each other at a single, indivisible part, i.e., at a point.

The trouble with this argument, however, is that it offends against certain divisibilist principles also established by the Philosopher. At the beginning of Physics 6, Aristotle argues that continuous magnitudes cannot be composed of indivisible points because indivisibles have no extremities (i.e., first and last parts) by means of which they could be continuous (meaning that their extremities are one) or even in contact (meaning that their extremities are together). ${ }^{8}$ Furthermore, continua must be infinitely divisible, because if they were divisible into indivisibles, we would per impossibile have indivisibles in contact with each other, since the extremities of what is continuous must be in contact with each other. ${ }^{9}$

7. Wodeham Quaestio de continuo (Murdoch and Synan p. 249, sect. 68). Compare Chatton Reportatio 2.2.3.1,4 as in Paris, BN lat. 15887, fol. 93rb-94va. I have abandoned the editors' suggested emendation of tenet for contingit in the third sentence of this passage. There is a refinement which should be mentioned, but which need not detain us. Although both were indivisibilists, Chatton, unlike Harclay, argued that continua were composed of a finite number of indivisibles in consecutive contact. For the details, see John Murdoch, "Infinity and Continuity," in CHLMP pp. 571-578, and Rega Wood, "Introduction" to De indiv., pp. 4-8.

8. See Physics 6.1 (231a21-b5).

9. Physics 6.1 (231b15-18). Although both Harclay and Chatton reject the first Aristotelian contact argument, only Chatton rejects the second. He does so by modifying Aristotle's definition of 'touch'. See second section, below, and Chatton Reportatio 2.2.3 (fol. 94vb). 
The indivisibilists who rejected Aristotle's contact argument did so for a variety of reasons: Harclay, to avoid the mathematical absurdity that would result if continua of unequal magnitude were composed of equally infinite parts; Chatton, as part of his defense of the theological doctrine of angelic motion; ${ }^{10}$ still others, because of difficulties they saw in Aristotle's own refutation of indivisibilism. ${ }^{11} \mathrm{My}$ aim here, however, is not to determine which theory, divisibilism or indivisibilism, is better suited to deal with various mathematical and theological constraints. ${ }^{12}$ Rather, I am interested in ontological constraints, and specifically in the way in which one group of divisibilists tried to reply to the indivisibilist touch-at-a-point argument without multiplying entities, viz. mathematical atoms.

A point of clarification: although the ontological question raised by the fourteenth-century divisibilist-indivisibilist debate over the structure of continua seems clear enough, this is not to suggest that rejection of indivisible entities is what nicely separates the nominalist position from all others. Parsimony can be achieved in a number of ways, of course, so that it would not have been inconsistent for a participant in the debate to express traditional nominalist scruples about the existence of universals, ${ }^{13}$ while still embracing mathematical atoms on the grounds that we cannot do without them if we want to explain the structure of continuous magnitudes. Moreover, although indivisibilism

10. Aristotle goes on to argue in Physics 6.10 (241a6-14) that it is impossible for anything indivisible to be in motion, an argument with obvious applications to angels, which are indivisible beings. Duns Scotus, for example, offers a mathematical argument against indivisibilism in the context of a discussion of angelic motion in Opus Oxoniense 2.2.9.

11. For discussion of the various contexts in which medieval indivisibilism was defended, see Murdoch and Synan, "Two Questions on the Continuum," pp. 212225; Murdoch, "Infinity and Continuity," pp. 575-577; and Wolfgang Breidert, Das aristotelische Kontinuum in der Scholastik (Munster: Aschendorff, 1970).

12. That task has already been embarked upon by others, and the story it reveals is in any case extremely complex. I direct the reader to John Murdoch's authoritative writings on this subject over the past quarter-century.

13. These scruples were often expressed in connection with Porphyry's first question about the nature of genera and species, "whether they subsist or are placed in bare [acts of] the understanding alone." See Boethius In Isagogen Porphyrii editio altera 1.10-11. Both Abelard and Ockham, for example, agree here that genera and species (1) exist in the understanding alone and (2) have no extramental significance except as conventional names. For discussion, see McCord Adams, William Ockham, pp. 312. 
was certainly the minority view, there were indivisibilists, such as Harclay, who held that universal terms do not signify anything real outside the mind, and divisibilists, such as Walter Burley (ca. 1275-1345), who defended a moderate realist position on the nature of universals. ${ }^{14}$ What this means is that there is no reason why the divisibilistindivisibilist debate could not have taken place as an in-house disagreement between one group of nominalists who thought it necessary to add indivisible entities to one's ontology for mathematical and/or theological reasons, and another group who rejected this. But at least by second quarter of the fourteenth century, it hardly ever did. Since most nominalists found it natural to identify with divisibilism, 15 the ontological aspect of the debate was not usually separated from it in practice. Indeed, the popularity of the problem of the existence of indivisibles is distinctively medieval, 16 and, as John Murdoch has suggested, may have been "to some extent a result of the kinds of questions about entities a particularist ontology urged one to ask."17

The three nominalist thinkers I shall be discussing-Ockham, Wodeham, and Buridan-all subscribed to a trio of doctrines characteristic, though (except for the first) by no means definitive, of fourteenth-century divisibilism: ${ }^{18}$

14. Although Harclay maintained that universal and particular terms are distinct only in reason, his view does represent, as McCord Adams has suggested, an "attempt to combine a nominalist ontology of singulars and concepts with a realist vocabulary" ("Universals in the Early Fourteenth Century," in CHLMP, p. 439). Accordingly, Harclay is best thought of as occupying a middle ground between moderate realists, such as Duns Scotus and Burley, and more radical nominalists, such as Ockham, who is unwilling to concede even that much. For discussion and references to the relevant texts, see McCord Adams, William Ockham.

15. The naturalness of the identification can be partly explained, no doubt, by the influence of Ockham's views on indivisibles. For discussion, see Murdoch, "Infinity and Continuity," pp. 574-575.

16. There is, for example, no direct treatment of the existence problem in Aristotle's Physics.

17. John Murdoch, "Scientia mediantibus vocibus: Metalinguistic Analysis in Late Medieval Natural Philosophy," in Sprache und Erkenntnis im Mittelalter, ed. Wolfgang Kluxen et al. (Berlin: Walter de Gruyter, 1981), p. 89, n. 43. Compare Murdoch, "William of Ockham and the Logic of Infinity and Continuity," in Infinity and Continuity in Ancient and Medieval Thought, ed. Norman Kretzmann (Ithaca: Cornell University Press, 1982), pp. 165-168 and 175-183.

18. For the variations on medieval divisibilism, see Murdoch, "Infinity and Continuity," pp. 571-584; Wood, Adam de Wodeham, pp. 10-15 (to whom the useful 
(1) Divisibilism: A continuum is not composed of atoms, but of parts divisible without end.

(2) Non-entitism: Indivisibles do not exist in the physical world.

(3) Infinitism: the composite parts of a continuum are infinitely divisible, or constitute a potentially infinite set.

The ontological question raised by the indivisibilist touch-at-a-point argument is especially worrisome for divisibilists who are non-entitists, of course, since it is not open to them to conceive of the point of contact between the sphere and plane as some kind of real limit. Despite their shared theoretical commitments, Ockham, Wodeham, and Buridan defuse the argument in surprisingly different ways. These differences cannot be explained, I think, solely by the various contexts in which the touch-at-a-point argument arose. Rather, as I hope to show, they demonstrate both the evolution and the increasing sophistication of explanatory methods used by fourteenth-century nominalist thinkers.

\section{WILLIAM OF OCKHAM}

William of Ockham discusses the indivisibilist sphere and plane example twice: once in the Expositio Physicorum, and once in the Quodlibeta septem. ${ }^{19}$ The first and more physicalistic context is in Book VI of the Expositio, a work directed in large part against

classificatory term 'non-entitism' is due). Duns Scotus, for example, rejected nonentitism, but is still classified as a divisibilist because he maintained that continua are not composed of indivisible entities. Scotus's arguments against non-entitism are cited verbatim and then attacked by Ockham in Tractatus de quantitate 1, in Opera Theologica 10, ed. C. A. Grassi (St. Bonaventure, N.Y.: Franciscan Institute 1986), pp. 26-45. The non-entitist form of divisibilism defended by Ockham, Wodeham, and Buridan was actually less common than the orthodox Aristotelian variety (whose defenders included Aquinas, Duns Scotus, and Giles of Rome), according to which indivisibles are to be understood as real limits, though not as constituent parts, of continua. In fact, the only non-entitist prior to Ockham seems to have been Peter John Olivi, for whom see Wood, Adam de Wodeham, p. 25, n. 44. The definition of divisibilism given here is that of Thomas Bradwardine (ca. 1295-1349), Tractatus de continuo (quoted in Murdoch, "Infinity and Continuity," n. 36): "continuum non componi ex athomis, sed ex partibus divisibilibus sine fine."

19. The argument is not mentioned in Ockham's other discussions of the structure of continua, namely in the Summa logicae and Tractatus de quantitate. The latter is his most comprehensive theological treatment of the continuum problem. 
Giles of Rome, a divisibilist who conceived of indivisibles as real limits based on the assumption that quantity is a res absoluta distinct from substance and quality. ${ }^{20}$ In Chapter 14, Ockham replies to Giles's view that, contrary to Aristotle, it is possible for indivisibles to be moved. ${ }^{21}$ Ockham notes that some have tried to refute this argument by proving that continua are composed of indivisibles, in connection with which he cites the following disjunctive argument for indivisibilism:

it is supposed that a completely spherical body touches an absolutely plane body. To which, I ask whether it touches at something divisible, or at something indivisible. The first cannot be given, because at whichever divisible you choose, there will be a curve, and consequently the whole [divisible] will not fit the plane, but there will be an intermediate body [corpus medium] between some part of the curve and that plane. If the second is given, we have what the argument proposes to show. 22

In other words, if we imagine a perfect sphere descending onto a perfectly plane surface beneath it, they must first touch at an indivisible point, because (ruling out compression or penetration) divisible

20. Giles was thus a divisibilist who rejected non-entitism. For discussion of the influence of Giles's views on Ockham in the Expositio Physicorum, see Ernest Moody, "Ockham and Aegidius of Rome," Franciscan Studies 9 (1949): 417-442. In contrast, Ockham denies that quantity is an absolute thing, distinct from substance or quality, and likewise rejects the notion that Aristotle meant to posit limits of continua really distinct from continua themselves. See Ockham Expos. Phys. 5.5.7, in Opera Philosophica 5, ed. Wood et al. (Bonaventure, N.Y.: Franciscan Institute, 1985), p. 382, lines 33-34. For discussion of Ockham's views here, see McCord Adams, William Ockham, pp. 201-213; Murdoch, "Infinity and Continuity," pp. 573-575; Murdoch, "Logic of Infinity"; and Eleonore Stump, "Theology and Physics in De sacramento altaris: Ockham's Theory of Indivisibles," in Infinity and Continuity, pp. 207-230, which takes issue with the interpretation offered in Murdoch, "Logic of Infinity."

21. Giles of Rome Commentaria in octo libros Physicorum Aristotelis 6.18 (Venice, 1502; rptd. Frankfurt a. M.: Minerva, 1968), fol. 160rb. Aristotle had argued in Physics $6.10(241 \mathrm{a} 6-14)$ that there can be no motion of a point or any other indivisible because before anything moving can traverse a space greater than itself, it must first traverse a space less than or equal to itself; but since there can be no space less than an unextended indivisible, the notion of a moving indivisible is incoherent. It is perhaps worth noting that Ockham, Wodeham, and Buridan were not about to deny the existence of immaterial indivisibles (e.g., angels or human intellectual souls) or, for that matter, the possibility of their motion. The touch-at-a-point argument, of course, concerns the necessity of positing indivisibles to explain the structure of continuous spatial magnitudes.

22. Ockham Expos. Phys. 6.14.4 (Wood et al. 583.63-68). 
curved parts do not "fit" divisible plane parts. Except for their single point of contact, there will always be space between them, and more space as one moves along the plane surface in any direction away from that point.

Ockham's reply to this argument is quick and direct. He denies that any two absolutely spherical and absolutely plane bodies can be said to touch, if by that we mean that there is no intermediate body between them. This is for two reasons. First, the sphere and plane cannot touch each other as a whole, since both are divisible entities composed of parts more immediate to their place of contact. Second, they cannot touch each other at some part, because any first touching parts of the sphere and plane you choose will be further divisible into smaller parts that touch each other even more immediately. Thus, if we call the first touching parts of the sphere and plane $A$ and $B$, respectively, Ockham says that it is "manifestly false" to suppose that there is nothing intermediate between any part of $A$ and $B$. He argues for this as follows:

each would be divided into three equal parts, viz. A into C, D, and E, and $B$ into $F, G$, and $H$. It is obvious that between $C$ and $F$ there is an intermediate body; for otherwise, they would be both curves or both planes. Therefore, A and B do not first touch each other. And so it can be proved of any parts that they do not first touch each other. . . . 23

Furthermore, to the counter-argument which supposes that a hard spherical body must immediately touch a soft plane bodily yielding easily to it (imagine a ball bearing dropped into a bowl of jello), Ockham replies that they would still not touch immediately, since there must always be an intermediate body between any sphere and plane parts you choose at the place of penetration. ${ }^{24}$

Ockham's reply here is interesting, to say the least. But one might argue that he arrives too quickly at what is, to be sure, a counterintuitive conclusion, namely, that "one must say, following Aristotle, that a purely spherical body cannot touch a purely plane body." 25 For it seems a kind of philosophical overkill to reply to the indivisibilist touch-at-a-point argument by saying that the sphere and plane do not

23. Ockham Expos. Phys. 6.14.4 (Wood et al. 583.83-584.87).

24. Ockham Expos. Phys. 6.14.4 (Wood et al. 584.101-115).

25. Ockham Expos. Phys. 6.14.4 (Wood et al. 584.98-100). 
touch each other at a point because they do not touch each other at all. Ockham is, of course, willing to say that the sphere and plane touch each other, if by that we mean that they touch "mediately," or in such a way that there are always other extended bodies between them. He apparently does not think it necessary to take some of the counterintuitive edge off the divisibilist solution by further exploring in his reply the notion of mediate contact. ${ }^{26}$ This is doubly unfortunate in view of Ockham's non-entitism, since a more precise definition of contact would surely help to explain the truth conditions of sentences such as 'The spherical and plane bodies are touching'. Unless predicates of contact can be assigned an interpretation that is both plausible and consistent with the assumption that indivisibles do not exist in the physical world, the indivisibilist query remains unanswered. If it is still true to say that continuous, divisible bodies touch at something, why not posit something, namely, indivisible points, at which they touch?

Ockham takes a more decided step towards addressing this issue in his reply to the touch-at-a-point argument in the Quodlibeta septem, a work composed after the Expositio Physicorum. Here his opponent

26. He does provide at least the beginnings of an account elsewhere in the Expositio physicorum, when he modifies Aristotle's definition of contact ("Things are said to be in contact when their limits are together," Phys. 5.3 [226b23]) to make it more amenable to his non-entitist brand of divisibilism. The reason seems clear. If by 'together' [rendered into Latin as simul] Aristotle means that their limits are in the same place, then the two things must be continuous. No two distinct things could touch each other in that sense without ceasing to be distinct. If two distinct things are to be in contact, then, their limits cannot literally be immediate, but only mediate. See Ockham Expos. Phys. 5.5.2 (Wood et al. 377.98-100 and 378.43-45). The conditional reflects Ockham's view that although Aristotle sometimes speaks as if points are things distinct from bodies, he does not mean this literally, as implying the existence of indivisible entities. See Ockham Expos. Phys. 5.5.2 (Wood et al. 377.38-378.42). Such remarks are rather to be treated as conditional propositions. This is also the intrepretation that Ockham suggests for mathematical propositions that mention indivisible points. Such points, he says, exist only in the imagination of the mathematicians. See Ockham Expos. Phys. 5.5.7, 5.7.1, 6.1.2 (Wood et al. 382.25-383.61, 402.28-31, 461.304-462.323). For discussion, see Murdoch, "Logic of Infinity," pp. 175-179. As we shall see below, Wodeham and Buridan also make use of the notions of mediate contact and entities indivisible only secundum imaginationem, respectively, but (unlike Ockham) they do so specifically in the course of their own non-entitist replies to the touch-at-a-point argument. 
is definitely Chatton, and his target is Chatton's version of the argument, which as we saw above concerns the hypothetical case of God placing completely spherical and completely plane bodies in contact with each other. To this argument, Ockham objects:

it is impossible and includes a contradiction [to say] that the sphere touches the plane, because if it does, since [it does] not [touch] at something indivisible, it must touch at a divisible part. And for any part of the spherical thing you choose, because it is part of something spherical, by necessity one part of it is ascending and another descending. And so by necessity there is some intermediate body [between them], say, the air, if it touches in the air. 27

Again, the curved surface of the spherical body will prevent it from being in contact with a plane at any of its divisible parts.

Yet Ockham also recognizes something in the Quodlibeta septem discussion that is present, but not made explicit, in his earlier treatment of the sphere and plane example: his conclusion that the sphere and plane would not touch is based on the indivisibilist assumption that contact must be immediate. "Otherwise," he says, "it can be said (and perhaps better) that a spherical body touches a plane at some divisible part of it." 28 That the latter is Ockham's preferred definition of contact is evident in the next paragraph, where there is a reply to the objection that the divisible part of the sphere actually touching the plane would not itself count as a spherical body, presumably because it would lack a curved surface. Ockham says that this follows only if we assume that

... some first part is touching as a whole, such that each part of that part touches the plane, since then the argument would conclude by necessity that it would not be completely spherical. ${ }^{29}$

It would follow, in other words, that no spherical part would touch any plane part if by 'touch' we mean contact between each and every divisible part of those parts. A glance at the curved surface

27. William of Ockham Quodlibeta septem 1.9 in Opera Theologica 9, ed. Joseph C. Wey (St. Bonaventure: Franciscan Institute, 1980), pp. 58-59, lines 200-205.

28. Ockham Quodl. 1.9 (Wey 59.205-207). For immediacy of contact as a characteristic thesis of indivisibilism, see Wood, Adam de Wodeham, pp. 3-10.

29. Ockham Quodl. 1.9 (Wey 59.210-212). 
of the sphere and the flat surface of the plane should be sufficient to confirm that.

Unable to talk about immediate contact between divisible parts, Ockham tries another strategy:

I now posit that [the sphere] does not touch by means of any first part of which each part touches the plane. Therefore, it does not touch by means of any first [part] that is prior to all other touching [parts]; but for any touching part you choose, still one half does not touch immediately, nor half of that half, and so on to infinity. 30

Ockham's view is that we can say that the sphere touches the plane as long as we do not mean that it touches immediately, or at any first part. His reasoning here reprises the argument from the Expositio Physicorum: any two parts of the sphere and plane taken to be immediate would be infinitely divisible into parts even more immediate, e.g., into halves, quarters, eighths, and so on.

Although Ockham considered these replies sufficient to refute the touch-at-a-point arguments offered by Giles and Chatton, ${ }^{31}$ his divisibilist and non-entitist successors do not seem to have regarded the issue as settled. Both Wodeham and Buridan take the indivisibilist sphere and plane example quite seriously, and, rather than merely repeating Ockham's arguments from the Expositio Physicorum and Quodlibeta septem, fashion their own positive accounts of how the sphere and plane may be said to touch. These seem intended to supplement Ockham's much briefer account in two ways: first, by precisely defining the divisibilist concept of mediate contact in the context of the touch-at-a-point argument; second, by turning the notion of the infinite divisibility of touching parts from a rough illustration into a quasi-mathematical procedure, thereby adding formal rigor to the non-entitist reply.

\section{ADAM WODEHAM}

Adam Wodeham focuses much more attention than Ockham on the indivisibilist sphere and plane example, quoting

30. Ockham Quodl. 1.9 (Wey 59.212-217), emphasis added.

31. See notes 22 and 7 above, respectively. 
directly from both the Harclay and Chatton versions of the touchat-a-point argument in his main discussion of the indivisibilist controversy, the Tractatus de indivisibilibus. ${ }^{32}$ Still, he prefers to call it a "common argument [communis ratio]" for the view that a point is an absolutely indivisible entity, a fact suggesting that, by the time Wodeham was writing, it had ceased to be associated with any particular indivisibilist thinker. ${ }^{33}$ Indeed, Wodeham observes that the question of whether the sphere would touch the plane or not "is a great point of dispute between [adherents of different] schools [of thought], and they make the difficulty emerge nicely for each side." 34

Wodeham argues, following Ockham, that either (1) it is not possible that the sphere touch the plane, or (2) if it does touch the plane, it touches it "at something infinitely divisible." 35 The second alternative, of course, involves the divisibilist concept of mediate contact. But before considering that, Wodeham offers an argument in defense of the first alternative, namely, that there can be no contact at an indivisible point.

Unlike anything in Ockham, this argument seems designed to confront Chatton's touch-at-a-point argument head on, even down to the way it sets up the sphere and plane example as a thought experiment about divinely produced ideal bodies. Wodeham asks us to imagine God placing a sphere at some distance above a plane in a medium of air, then causing the sphere to descend until it is prevented from descending further by the surface of the plane, but

32. See Harclay's version in Wodeham De indiv. 1.2.4 (Wood); and Chatton's in Wodeham De indiv. 1.2.16 (Wood 94.18-24, 100.14-17). The Chatton version quoted by Wodeham is not exactly the same as the version cited in note 7 above. It involves, like the Harclay version, a sphere being moved across a plane surface. For the source of the latter, see Chatton, Reportatio 2.2.3 (fol. 94va); of the former, note 6 above. Both versions of the indivisibilist argument are likewise reproduced by Wodeham in his Quaestio de continuo (Murdoch and Synan, "Two Questions on the Continuum," pp. 276 , sect. $24 ; 280$, sect. 34 ). Wodeham also considers the question of indivisibles and the composition of continua in his Lectura secunda 24.1-2, ed. Rega Wood and Gedeon Gàl (St. Bonaventure: Franciscan Institute, 1990) 3:321411 , although the sphere and plane example is not discussed there.

33. Wodeham De indiv. 2.2.3 (Wood 138.26). Wood argues that it was composed between 1323 and 1331, probably closer to the earlier date (pp. 15-16).

34. Wodeham De indiv. 2.3.4 (Wood 146.7-8).

35. Wodeham De indiv. 2.3.3 (Wood 146.5). 
without either body suffering compression or penetration. "This once accomplished," Wodeham argues, "the air interposed would still be continuous, although not everywhere uniformly or equally thick, but always thinner or more and more tenuous, as we approach the place of contact." 36 To demonstrate this conclusion, Wodeham embellishes his thought experiment as follows:

suppose that God annihilates that spherical body and the plane joined to it in the manner described above, without effecting any change of place in regard to the air, one part of which previously surrounded the spherical body and the other part of which touched the plane surface[namely], the solid plane body previously withdrawn [below] the spherical body. Once this is done, I ask: will we find that that air is continuous or not? [1] [If it is continuous, then] this is what we proposed to show. [2] [If it is not continuous], then there will be a hole, either a divisible or indivisible hole. [2.1] [If it is divisible], then either [2.1a] there was a vacuum there before, which appears incongruous; or [2.1b] the plane was immediately touched by the sphere divisibly in a straight line, which is contrary to the nature of sphericity and of a straight line. [2.2] If [the hole is] indivisible, then it could be filled by an indivisible; or at least there would be an indivisible vacuous space, where before there had stood an indivisible belonging to the spherical body joined to the plane. And the opposite of this was proven above. 37

The problem with the indivisibilist option [2.2] is that since indivisibles cannot together make something continuous, ${ }^{38}$ indivisible points cannot be part of any continuum, such as the sphere; hence, their annihilation would make no difference to the way in which the sphere touches the plane. ${ }^{39}$

But even if the continuity of the air, in this example, shows that the sphere and plane cannot touch in the way Harclay and Chatton want them to touch, Wodeham still hopes to make sense of our intuition that they must touch somehow. Here he has a twofold

36. Wodeham De indiv. 2.3.6 (Wood 146.24-27).

37. Wodeham De indiv. 2.3.7 (Wood 146.32-35 and 148.1-10).

38. Wodeham De indiv. 2.1.7-8 (Wood 124.10-27). Wodeham refers to a preceding argument at De indiv. 1.3.1 (Wood 102.1-13), as well as quoting from Ockham's argument that an indivisible point cannot be posited as part of something existing per se. For the latter, see Ockham Expos. Phys. 6.1.2 (Wood et al. 454.57-65).

39. Wodeham De indiv. 2.3.3 (Wood pp. 144-146). 
strategy. First, tempered by (of all things) Chatton's indivisibilism, he takes Ockham's notion of mediate touching as contact at some divisible part, but not at any first such part, and he refines it into a new account of touching which further modifies the Aristotelian notion of contact so that he can talk about divisibles being immediate to each other. Second, he introduces the quasi-mathematical procedure he calls "proportional division ad infinitum" to illustrate how the sphere and plane could be said to touch by means of a divisible, but in the manner of an indivisible. Wodeham begins by noting that in his argument against indivisibilism, it also follows that the sphere and plane do not touch at anything divisible. For the reason, he refers the reader first to Ockham's Expositio Physicorum argument that between any two "first" touching parts of divisible bodies, there will always be a corpus medium, or intermediate body. ${ }^{40}$ For Wodeham, however, the real source of the problem is what he takes to be Aristotle's definition of contiguous contact. The sphere and plane do not touch each other, he says, if

we understand by 'touch each other' that their limits are together and in the same primary place according to the description of contiguous things laid down by Aristotle in Physics 5 and repeated in book 6. 41

According to Aristotle, however, things are contiguous if they are (1) in succession (nothing of their own kind is intermediate between them), and (2) in contact, or touching (their extremities are together), ${ }^{42}$ suggesting that Wodeham has run together Aristotle's definition of contact (things are touching if their extremities are together) with his definition of continuity (things are continuous if their extremities are one). ${ }^{43}$ No divisibles can be contiguous on this understanding of Aristotle because divisibles have spatially distinct parts, and it is not possible for two things having spatially distinct

40. See notes $23-24$ above.

41. Wodeham De indiv. 2.3.11 (Wood 150.6-9).

42. Aristotle. Phys. 5.3 (227a9).

43. See Aristotle. Phys. 5.3 (226b21-227a9); 6.1 (231a21-29). Compare Wodeham De indiv. 2.3.11 (Wood 151.13-14): "no such [sphere and plane] limits are together in that fashion." The source of Wodeham's (perhaps deliberate) confusion here might well have been Ockham, who likewise found it necessary to reinterpret the Aristotelian notion of contact so that it would apply to non-continuous divisible bodies. 
parts to occupy "the same primary place." Nevertheless, Wodeham uses the occasion to offer his own, alternative definition of 'touch each other'. This definition is interesting because it looks very much to have been inspired by his indivisibilist arch-rival, Chatton, who had tried to refute Aristotle's contact argument with the novel assumption that continua can be composed of indivisibles not in the sense that they are in the same place (which is, after all, why Aristotle found indivisibilism to be absurd), but in the sense that they are next to each other such that whole touches whole without there being anything else in between. ${ }^{44} \mathrm{~W}$ ith Chatton, Wodeham proposes that "things 'touching each other' or 'contiguous' are those whose limits are together, or [whose limits] are immediate [to each other]" by what he terms a "simultaneity or positive immediacy [simultate seu immediatione positiva]." 45 The sphere and plane would touch each other in this sense, he says, since each extends to the other without stopping short of, or extending beyond, the other. ${ }^{46}$ But what, exactly, is the significance of them touching with "simultaneity or positive immediacy"?

Wodeham attempts to answer this question in a further step, illustrating the notion of contact between positively immediate limits by means of a procedure he calls "proportional division ad infinitum." Although neither the sphere nor any part of it touches the plane "primarily and exactly [primo et adaequate]," he says, it does touch by itself and in its parts, viz. "by any part of it extending to and reaching the plane." 47 Thus, the sphere and plane can be said to touch each other immediately if the sphere and each part of it is treated as a kind of macro-indivisible, extended towards the plane until

44. Chatton Reportatio 2.2.3 (fol. 94vb): “. . . placet mihi quod totum tangat totum, id est quod nihil est medium inter ea." Wodeham, who was intimately familiar with Chatton's writings, quotes directly from this passage at De indiv. 1.1.24 (Wood 48.58 ). The source of Chatton's alternative definition of contact (though not, of course, its application to indivisibles) could well have been Ockham. See Ockham Expos. Phys. 5.5.2 (Wood et al. 377.98-100, 378.43-45).

45. Wodeham De indiv. 2.3.12 (Wood 150.17-18). Chatton, of course, characterizes such contact negatively, namely as involving "nothing else in between" things that are touching, rather than positively, as is suggested by the notion of positive immediacy.

46. Wodeham De indiv. 2.3.12 (Wood 150.18-20).

47. Wodeham De indiv. 2.3.14 (Wood 150.34 to 152.1). 
it can go no further without compression or penetration. ${ }^{48}$ And there are infinitely many such positively immediate limits:

For example, [a sphere would touch a plane] by means of its [lower] half, constructed transversely; and by means of a half of that same [half] constructed in parallel-[that is], the lower half similarly reaching the plane, and so on ad infinitum, as can be proven by argument and also using the examples introduced above here. 49

We might illustrate Wodeham's procedure as follows: a perfect sphere and the plane on which it rests would, ruling out compression or penetration, touch each other immediately, since the sphere would be extended towards its place of contact with the plane. But if we were to divide the sphere by slicing it horizontally through its middle, thus removing its top half, no change would be effected in the way the remaining half-sphere touches the plane, and so it, too, would touch the plane immediately. But then we can use the same procedure to produce a quarter-sphere having the same manner of contact, and then an eighth-sphere, and so on ad infinitum. And furthermore, adds Wodeham, we can say the same thing "analogously regarding the parts of the plane touched by the sphere." 50 Wodeham's non-entitist reply to the indivisibilist touch-at-a-point argument is that although we must say, following Ockham, ${ }^{51}$ that the sphere always touches the plane either as a divisible whole or at some divisible part (and there are infinitely many such divisible parts in contact with the plane, as

48. I owe the term 'macro-indivisible' to Norman Kretzmann, "Adam Wodeham's Anti-Aristotelian Anti-Atomism," History of Philosophy Quarterly 1 (1984): 388.

49. Wodeham De indiv. 2.3.14 (Wood 152.1-5).

50. Wodeham De indiv. 2.3.15 (Wood 152.12-13). Wodeham contends that proportional division ad infinitum can likewise be applied to the diameter of the sphere perpendicular to the plane. See the passage at De indiv. 2.3.16 (Wood 152.14-22). Wodeham's solution here appears to involve the mathematical notion of asymptotic division to a limit. His assumption (via his definition of mediate contact) would be that angles of tangency have a finite minimum limit, whereas one would expect an indivisibilist to argue that such angles are of infinitesimal magnitude. For a discussion of curvilinear angles and their relation to the continuum problem, see Murdoch, "Infinity and Continuity," pp. 580-582.

51. Wodeham mentions Ockham by name in this context at De indiv. 2.3.18 (Wood 154.6-7). He appears to have in mind Ockham's handling of the indivisibilist touch-at-a-point argument in Expositio Physicorum 6. 
the method of proportional division demonstrates) it does so in the manner of an indivisible. 52

What Wodeham has done here, I believe, is to combine, rather ingeniously, Ockham's thoroughly divisibilist and non-entitist account of continua with a definition of contact inspired by Chatton's explanation of how continua can be composed of indivisibles (pace Aristotle), in order to suggest a way in which divisibles can be said to touch each other positively and immediately. ${ }^{53}$ It is as if Wodeham were saying, "I know that no two absolutely spherical and absolutely plane bodies can be said to touch each other if by that we mean that there is no intermediate body between them. After all, each is divisible into infinitely many parts that touch each other with greater and greater immediacy. But if we think of them just as wholes, as Chatton conceives of indivisible points existing next to each other in a continuum, then they can touch each other immediately in the positive sense that each is extended towards the other as far as it can go, without compression or penetration." What Wodeham borrows from Chatton is a way of thinking about the composition of continua which he then applies to divisibles. Though de facto divisible, continua (or their parts produced by proportional division) are to be thought of as indivisible wholes, a move which enables the non-entitist to talk about immediate contact between continuous bodies while shielding his claims from being reduced to absurdity by Ockham's argument.

But non-entitist and indivisibilist alike may object that it is wrong to speak of the sphere and plane touching each other immediately, especially in view of Wodeham's earlier concession that there will always be a continuous body of air between them. Chatton in particular might want to stress that, on his definition of contact, there is nothing between the immediately touching indivisible points of which continua are composed. But Wodeham could handle such objections

52. Wodeham De indiv. 2.3.18 (Wood 152.32-34).

53. Again, Wodeham not only knew Chatton's definition of contact, but quotes from it directly near the beginning of the De indiv. See note 44 above. In a note on Wodeham's second definition of contact, Wood assumes (correctly, in my view) that "'positive immediacy' means that the immediate things are together, as opposed to there being nothing between them." She does not, however, make the further suggestion (which I am making here) that Wodeham got the idea from Chatton. 
with a neat distinguo. First, he would say, if you are talking about the sphere and plane as divisible entities, then of course they will touch each other only mediately because any sphere and plane parts you choose will have more immediate parts, to say nothing of the air, between them. But if, on the other hand, you are talking about the sphere and plane (or of any of their parts produced by proportional division) as wholes, then the divisibilist reductio argument no longer applies, and we must instead define immediacy in terms of their being so close to each other that, if they were any closer, their sphericity and/or planeness would be compromised by compression and/or penetration. That this latter, immediate sense of contact is compatible with the former, mediate sense is something Wodeham concedes in the final section of his discussion of the sphere and plane when he remarks, "and nevertheless, as was made clear [i.e., in the refutation of the indivisibilist touch-at-a-point argument], something mediates, or could mediate, between any part touching the plane in this fashion and the plane, when there is such contact." 54 That is, the sphere and plane can still touch each other immediately as wholes, even though there is air between them.

The influence of this novel strategy for defusing the sphere and plane example is evident in the writings of Wodeham's somewhat younger Parisian contemporary, John Buridan. Buridan's writings suggest that he adopted not only Wodeham's indivisibilist-inspired definition of immediate contact, but also the method of proportional division ad infinitum as an illustration of how the parts of divisible bodies can be said to touch each other. Yet Buridan did not embrace Wodeham's reply to the indivisibilist argument without first augmenting and refining it. It is to that final part of our story that I now turn.

\section{JOHN BURIDAN}

Buridan is more interested than either Ockham or Wodeham in exploring the logico-semantic underpinnings of the debate over the structure of continuous magnitudes. He sees the indivisibilist touch-at-a-point argument primarily as presenting the problem

54. Wodeham De indiv. 2.3.19 (Wood 154.16-18). 
of how a non-entitist should understand the terms occurring in it, i.e., 'point' and 'touch', rather than as raising questions about the mode of contact between ideal spheres and planes. The logical and mathematical aspects of the problem are related, or course, but the difference we see in Buridan is one of emphasis. "If only we could be clear about the signification of our terms," he seems to be saying, "such mathematical questions about modes of contact will answer themselves."

Buridan's approach is best exemplified in Book 6 of his Questions on Aristotle's Physics, where the sphere and plane example is mentioned in an argument on the affirmative side of Question 4, which asks whether points are indivisible things [res indivisibiles] in a line. 55 After presenting and defending his own divisibilist, non-entitist, and infinitist views on the question, Buridan proceeds to reply to the arguments on the opposing side. To the touch-at-a-point argument, he replies as follows:

As for the sphere placed on the plane, we say that the whole sphere touches the whole plane, taking 'whole' categorematically. But it is not the case that the whole sphere, or some whole part of the sphere, touches the plane, taking 'whole' syncategorematically. Indeed, no part of the sphere taken syncategorematically touches the plane, except the last [part] next to that plane. And we wish to signify these concepts [intentiones] when we say that it touches at a point. ${ }^{56}$

So would a sphere placed on a plane surface touch it at a point? Buridan is willing to say, following Wodeham, that they touch each other as wholes, but only if the term 'whole' is understood in its categorematic sense, which he elsewhere says should be expounded as 'having parts'. ${ }^{7}$ In this way, the proposition 'The whole sphere

55. The argument Buridan presents here looks like a minimalist version of the Harclay/Chatton touch-at-a-point argument. See Buridan Quaestiones super octo physicorum libros Aristotelis 6.4, in Kommentar zur Aristotelischen Physik (Frankfurt a. M.: Minerva, 1964), fol. 96rb. Buridan's clipped rendering of the argument both here and in his other writings suggests that it had perhaps acquired in mid-fourteenth-century Paris the same status Wodeham had earlier ascribed to it in England, namely that of a "common argument" (communis ratio) for indivisibilism.

56. Buridan Q. in Phys. 6.4 (fol. 97vb).

57. Buridan Quaestiones in De anima 2.7, ed. Peter Gordon Sobol, in "John Buridan on the Soul and Sensation: An Edition of Book II of His Commentary on Aristotle's 
touches the whole plane' is true if sphere and plane are both seen as wholes having parts, namely, as divisible wholes. But if 'whole' is understood in its primary syncategorematic sense, ${ }^{58}$ where it is expounded as 'each part', it will distribute the predicate 'touches the whole plane' over each and every integral part of its subject. The proposition will thus be false, because only the last part of the sphere immediately next to the whole plane would touch it in that sense. Furthermore, since Buridan maintains that continua are infinitely divisible, nothing answers to the description, 'last part of the sphere', if by that we mean 'whole last part' in the latter, syncategorematic sense. Buridan explains this consequence in an argument reminiscent of Ockham's proof that infinitely divisible spheres and planes cannot have any first touching parts:

no whole part of any continuum is its limit [terminus], and I am [here] taking the name 'whole' syncategorematically. This thesis is obvious because no whole part is the first or last. For which reason, assume the opposite, viz. that some whole part of any continuum is its first or last part. It follows that each part of that part will be the first or last, and that it will be the limit of that continuum. And this is false, because if the part which is posited first were divided into $A$ and $B$, it is certain that $A$ will be before $B$, and so $B$ will not be the first part. 59

Buridan therefore sees the problem of the sphere touching the plane in terms of the logical distinction between categorematic and syncatgorematic words. We can talk about whole continuous entities in contact with each other as long as 'whole' is taken in its categorematic, divisibilist sense of 'having parts'. But we cannot do so if we assume, following the indivisibilists, that there is some whole indivisible part

Book of the Soul, with an Introduction and a Translation of Question 18 on Sensible Species," doctoral dissertation, Indiana University, 1984, pp. 103-104; Tractatus de suppositionibus 3.7, ed. Maria Elena Reina in Rivista critica di storia della filosofia 12 (1957): 326, lines 482-483.

58. In its primary syncategorematic sense, 'whole' effects a distribution over the integral parts of its subject. See (for Buridan's discussion of this sense) Q. in De anima 2.7 (Sobol pp. 102-105); Tractatus de suppositionibus 3.7 (Reina 326.490495). For general discussion, see Norman Kretzmann, "Syncategoremata, Exponibilia, Sophismata," in CHLMP, pp. 230-240.

59. Buridan Q. in Phys. 6.4 (fol. 97ra). This is the seventh thesis (conclusio) defended by Buridan in the main part of the question. 
of the sphere in the syncategorematic sense that each part of it is in contact with the plane. This is because indivisibles by definition have no parts.

What is the point of such precision? In a comment just prior to his discussion of the sphere and plane example, Buridan reveals that his aim is to underwrite certain figurative modes of discourse. The logicosemantic problem here is that even if the last part of a continuum is called a point in the divisibilist, categorematic sense that some whole part of it, i.e., some part of it having parts, is its last part, "a point is commonly said by everyone to be indivisible." 60 To this Buridan replies that a point is called an indivisible "not because it is so, or because it is literally true [quia sit ita, vel quia sit verum de virtute sermonis]" that a point is indivisible, ${ }^{61}$ but because it is treated as such in conventional usage. He gives several examples here, the first and foremost of which has to do with the practice of mathematics. Although points are not strictly speaking indivisible,

in one way, this is said in keeping with the imagination of mathematicians [secundum imaginationem mathematicorum], as if there were an indivisible point, not because they must believe that there really is, but because they revert to those assumptions in measuring, just as if it were so. For if an indivisible point is limiting a line, it is agreed that that whole line would be exclusively beneath it, and likewise, the whole [line] itself is exclusively beneath its last part. ${ }^{62}$

Likewise, says Buridan, we observe that in commerce, a cloth merchant measures lengths of cloth from an imaginary first point. ${ }^{63}$ In more philosophical contexts, we see that a point is sometimes called

60. Buridan Q. in Phys. 6.4 (fol. 97 rb).

61. Buridan Q. in Phys. 6.4 (fol. 97 rb).

62. Buridan Q. in Phys. 6.4 (fol. 97rb-va). Compare Buridan Quaestiones super libros quatuor De caelo et mundo 1.22, ed. Ernest A. Moody (Cambridge, Mass.: Medieval Academy of America, 1942), pp. 105, 112-15; and Ockham Expos. Phys. 5.5.7 and 6.1.2 (Wood et al. 383.48-49, 462.320-323), discussed in note 26 above.

63. Cloth merchants aren't worried about the structure of continua, of course, but (and this is Buridan's point) the practice of measuring an ell of cloth clearly assumes the existence of indivisible first and last points. If such points are treated as infinitely divisible, how could they give rise to determinate and non-arbitrary measurements? For analogous remarks regarding the utility of other concepts of measurement, e.g., length, width, and depth, none of which Buridan supposes to be really distinct from quantity, see Q. in De caelo 1.2-3 (Moody pp. 10-16, esp. 15.29-33). 
the indivisible limit of a line in the sense that "it is not divisible into parts of which each part is the limit of the line." In other words, 'point' can refer to some whole last part of a line in the categorematic but not the syncategorematic sense of 'whole'.64 Alternatively, the first or last part of a line is sometimes treated as a single thing distinct from every other part, in which case it would acquire the qualitative or formal indivisibility Aristotle ascribes in Metaphysics X to that which is one. ${ }^{65}$ Like the cloth-merchants, mathematicians and philosophers sometimes ply their trade on the assumption that points are indivisible.

Buridan's sensitivity to the logico-semantic underpinnings of mathematical language enables him to appreciate an aspect of the sphere and plane example missed by both Ockham and Wodeham. This emerges in Buridan's reply to the touch-at-a-point argument in his "Quaestio de puncto," an independent treatise on the continuum problem. ${ }^{66} \mathrm{He}$ begins by citing Averröes's comment that although natural bodies can touch only at a divisible part, a geometrically conceived sphere and plane surface would touch at a point. ${ }^{67}$ Accordingly, Buridan concedes that there is indeed a sense in which continua must be assumed to be in contact at a point.

64. Buridan Q. in Phys. 6.4 (fol. $97^{\mathrm{rb}}$ ).

65. Buridan Q. in Phys. 6.4 (fol. 97va). See Aristotle Metaph. 10.3 (1054a20-29).

66. The Quaestio de puncto asks essentially the same question as $Q$. in Phys. 6.4, namely "whether a point is some indivisible thing added to a line or body." See Buridan Quaestio de puncto, ed. V. Zoubov in "Jean Buridan et les concepts du point au quatorzième siècle," Mediaeval and Renaissance Studies 5 (1961): 63, line 3. Though there are similarities between the two discussions, the actual texts differ in both their structure and argument. The editor of the De puncto prefers to describe them as "complementary" (Zoubov p. 46). Unlike Q. in Phys. 6.4, the De puncto is directed against a certain "doctor venerabilis" who is not further identified. The author of the table of contents of the volume in which one of the manuscripts of the De puncto is found (Paris, BN lat. 16621) calls it a treatise written "contra magistrum de Montescalerio" (Zoubov, "Jean Buridan," p. 43). Michalski has suggested that the magister in question is Burley. The editor of the De puncto regards this as a possibility, but also maintains (sensibly, in my view) that it cannot have been the entire aim of the De puncto to refute Burley. See Zoubov, "Jean Buridan," pp. 50-52.

67. Buridan De puncto 3.2 (Zoubov 91.21-25). The editor of the Quaestio de puncto gives the reference to Averröes as In De coelo 1.32 (Venice, 1560), 5:27r. The touch-at-a-point argument is presented in highly abridged form at De puncto 3.1 (Zoubov 85.10). 
in order to verify the thought of the mathematicians, you must know that when a body is touching another body, it touches the other as a whole_taking 'whole' unitively [unitive] — because the body that is one whole touches the other body that is also one other whole, but not as a whole dividedly [divisive], because this would signify that each part would touch each part, which cannot be without penetration. ${ }^{68}$

The upshot for the sphere and plane example is clear.

if a spherical body is placed on a plane, they would not touch each other in their parts by any division. And so they are said to touch at a point. ${ }^{69}$

The similarity between these remarks and Wodeham's view, namely, that spheres and planes conceived as positively immediate macroindivisibles would touch each other at a point, can hardly be accidental. Like Wodeham, Buridan stresses that continua said to touch at a point must be thought of positively as wholes, rather than negatively as mere aggregates of parts producible by division. But this is not simply an endorsement of Wodeham's position. Buridan adds sophistication to the non-entitist reply in two ways. First, like Wodeham, he shows that Ockham's counterintuitive denial of contact is not the only option available to the non-entitist: by exploiting the logical distinction between the categorematic and syncategorematic senses of the term 'whole', one can show how the touch-at-a-point argument is actually compatible with divisibilist and non-entitist assumptions about the structure of continua. Second, Buridan sees this compatibility as exemplified in the practice of mathematicians, who use terms such as 'point' connotatively to refer not to a new class of entities, but to already existing entities in a certain, abstract way, namely, as quantities. ${ }^{70}$

68. Buridan De puncto 3.2 (Zoubov 91.26-92.1).

69. Buridan De puncto 3.2 (Zoubov 92.14-15).

70. Buridan In Metaphysicen Aristotelis quaestiones argutissimae magistri Joannes Buridani 6.2 (Paris: 1588 [actually 1518]), rptd. as Kommentar zur Aristotelischen Metaphysik

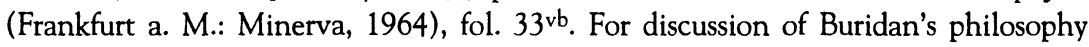
of mathematics, see J. M. M. H. Thijssen, "Buridan On Mathematics," Vivarium 23 (1985): 55-78. Though Buridan is parsimonious about positing entities, he sees nothing wrong (unlike Ockham) with proliferating modes of entities to account for the truth conditions of sentences concerning certain kinds of physical change. See Q. in Metaph. 5.8, Q. in Phys. 2.3. For discussion, see Calvin Normore, "Buridan's Ontology," in How Things Are: Studies in Predication and the History and Philosophy 
That Buridan eventually came to develop his account into something of a fine art is evident in one of his last works: Book 3, Question 14 of the third and final redaction of his Questions on Aristotle's De anima. ${ }^{71}$ After discussing the ways in which indivisibilists and divisibilists nominally define the term 'point', he notes that "students have occasionally asked whether a sphere placed on a plane would touch it at a point." To this query, he offers a split reply, depending upon which nominal definition of 'point' is used. ${ }^{72}$ If 'point' is defined in the indivisibilist sense as 'an indivisible having position in a magnitude', he says, then a sphere placed on a plane surface would not touch it at a point, since "a point is nothing," and touching obviously involves something. Recall that this is essentially Ockham's reply to the argument: if contact has to be at a point, then there can be no contact. But if 'point' is defined in the divisibilist sense as 'the first or last part of a line', Buridan replies conditionally, stating that "if it touches, it touches it at a point in such a way that it touches at [the sphere's] last part." Not only that, it touches "at infinitely many last parts," since the sphere has infinitely many last parts, which may be produced, he says, "by dividing the sphere at circles parallel to each other and to the plane itself"-in other words, by slicing the sphere horizontally so that the cuts are parallel to the plane on which it rests. This is, of course, the method of proportional division ad infinitum

of Science, ed. James Bogen and J. E. McGuire (Boston: Reidel, 1985), pp. 189-203; and Zupko, "How Are Souls Related to Bodies? A Study of John Buridan," Review of Metaphysics 46 (1993):575-601. For Ockham's contrasting views on this point, see McCord Adams, William Ockham, pp. 178-186 and 277-285. Buridan also sees mathematical or, more properly, geometrical terms such as 'sphere' and 'plane' as referring to natural entities conceived in a certain abstract and generalized manner, namely, in so far as they exhibit the inherence of a magnitude. One might say that Buridan proliferates 'hows' rather than 'whats'. See, e.g., Buridan De puncto 1.1 (Zoubov 65.10-15). I should perhaps add that Buridan's strategy here would be of little use to Ockham, and not merely because Ockham balks at proliferating modes. The traditional interpretation of the role of connotative terms in Ockham's ontological program (as strictly synonymous with their nominal definitions, and hence as eliminable in mental language), has been recently, and very effectively, criticized by Claude Panaccio, "Connotative Terms in Ockham's Mental Language," Cahiers d'épistémologie [Montreal] no. 9016 (1990): 1-21.

71. For evidence suggesting that Buridan's $Q$. in De anima was composed after May 1347, see Zupko, "John Buridan's Philosophy of Mind," doctoral dissertation, Cornell University, 1989, pp. xxii-xxiii.

72. Buridan Q. in De anima 3.14 (Zupko 155.98-156.110). 
Wodeham uses to illustrate how the notion of contact at some whole part of the sphere is compatible with the divisibilist assumption that the sphere has infinitely many such parts. Thus, says Buridan, a sphere sliced in half would touch the plane at the point which is its bottom half; the sphere sliced in quarters would touch the plane at the point which is its bottom quarter; and so on ad infinitum.

All of this is, Buridan concedes, subject to the condition that the sphere does touch the plane. Should the objector be dissatisfied with this hypothetical reply, and "ask categorically whether [the sphere] touches [the plane surface at a point]," Buridan has a second twofold reply, depending this time on the nominal definition of the word 'touch'. ${ }^{73}$ If the definition is based on Aristotle's remark in Physics 5 that two things touch if their extremities are together, ${ }^{74}$ then we need to ask about the nominal definition of 'together'. Buridan says that 'together' can be defined in terms of 'adjacent'. The latter term, it appears, has an ambiguous signification: it could signify either (1) two bodies such that no other body is between them; or (2) the situation of two bodies such that they could not be closer "without the penetration or compression of one of them." 75

If 'adjacent' signifies in the second way, Buridan says, "the sphere and the plane would touch each other." Contact of this sort is defined using Wodeham's notion of positive immediacy: the sphere and plane are said to touch if they extended towards each other as far as possible without compression or penetration, regardless of presence of other, intermediate bodies (e.g., the air) between them.

But if 'adjacent' signifies in the first way, Buridan argues that the sphere and plane "do not touch each other" because then they would have to touch at a point, which is nothing.

if you place an actual sphere above an actual plane here in the air, then there will be air between them and between any and every part of them, because the air on the right would touch against the air on the left, for if

73. Buridan Q. in De anima 3.14 (Zupko 156.111-124). Compare Buridan De caelo 1.22 (Moody 107.31-32); Ockham Expos. Phys. 5.5.2 (Wood et al. 377.98100); Wodeham De indiv. 2.3.11 (Wood 151.13-14).

74. See Physics 5.3 (226b23).

75. Although Buridan does not acknowledge his sources here, we can easily recognize the former as Chatton's negative definition of contact between indivisibles, and the latter as Wodeham's positive definition of contact between continuous wholes. 
there were indivisible points as some imagine, those volumes of air would be separated only by a single indivisible point, which would not separate the parts joined to it. And since there would be nothing indivisible in the sphere or in the plane, and air is between any indivisible of that sphere and of that plane, it follows that there is nothing belonging to the one that is touching something belonging to the other in such a way that there is not some body between them, namely, the air. ${ }^{76}$

In other words, if we imagine the cross-sectional view of an actual sphere $S$ being lowered onto an actual plane $P, S$ and $P$ will be separated by a continuum of air-call it ' $L R$ '-as long as $S$ is above $P$. But when $S$ has been lowered as far as it can go, $L$ and $R$ would be separated, the case assumes, only by the point of contact between $S$ and $P$. But since this same point is also the point of contact between $L$ and $R, S$ cannot really touch $P$, for the continuum $L R$ still separates them. Therefore, $S$ and $P$ cannot touch at a single, indivisible point. To divide these volumes of air, that point would have to be extended and hence divisible-something Ockham and Wodeham also both recognized.

\section{CONCLUSION}

The replies of Ockham, Wodeham, and Buridan to the indivisibilist touch-at-a-point argument based on the sphere and plane example show, on a small scale, how medieval divisibilism evolved from a relatively unsophisticated defense of Aristotelian assumptions into a highly complex and subtle theory about the structure of continua. The portion of the story l've told appears to go something like this: in Ockham, the indivisibilist argument is addressed mostly in terms of definitions and arguments from Aristotle's Physics, with little concern about its initial or intuitive plausibility. In Wodeham, that plausibility is both confronted and resolved in terms of an alternative account of contact (inspired, ironically, by the indivisibilists), and by means of the quasi-mathematical technique known as "proportional division ad infinitum," which is used to illustrate how the sphere and plane can be said to touch by means of a divisible, but in the manner

76. Buridan Q. in De anima 3.14 (Zupko 156.124-157.134). 
of an indivisible. Finally, in Buridan, the conclusion of the argument is treated like a sophism sentence and disarmed using logic, so that the paramount concern is to understand the signification of terms such as 'point' and 'contact'. The mathematical problem of explaining contact between ideal continuous bodies is raised only secondarily, almost as an afterthought. The divisibilist and non-entitist solution is hardly free of counterintuitiveness, of course, since it stipulates that if 'point' is to be a referring expression, it must pick out some divisible macroobject. From a dialectical standpoint, however, what really blunted the force of the indivisibilist touch-at-a-point argument was the development by Wodeham and Buridan of particular methods by which it could be interpreted without positing indivisible entities. In the fourteenth-century debate over the structure of continua, nominalism did indeed meet indivisibilism, and at least in the case of the touchat-a-point argument, it emerged with its ontology intact. ${ }^{77}$

San Diego State University

77. For comments on previous drafts of this paper or arguments contained therein, I would like to thank Mary Gregor, Norman Kretzmann, Tom Weston, and Rega Wood. An abridged version was presented at a session on medieval metaphysics at the 1992 Annual Meeting of the Medieval Association of the Pacific at the University of California, Irvine. I am grateful to several members of the audience on that occasion, especially Marilyn Adams, Calvin Normore, and Martin Tweedale, for a number of helpful suggestions. 